\title{
Estimation of relative economic weights and the marginal willingness to pay for breeding traits of Brown Swiss cattle using discrete choice experiments
}

\author{
A. Just, ${ }^{1}$ R. Wellmann, and J. Bennewitz \\ Institute of Animal Science, University of Hohenheim, Stuttgart 70599, Germany
}

\begin{abstract}
Breeding traits are usually combined in a total merit index according to their economic weights to maximize genetic gain based on economic merit. However, this maximization may not always be the aim of the selection decisions by farm managers. A discrete choice experiment was used to evaluate the importance of traits in terms of the selection decisions of farm managers operating in different environments. Six trait complexes, the semen price, the interactions between these traits, and significant characteristics of the farms were included in a conditional logit model to estimate relative economic weights and the marginal willingness to pay for all traits. Milk value, conformation/udder, and fitness were the most important traits for the farmers, and significant interactions indicated that fitness is of greater importance on organically managed farms than on conventional farms. Farm managers with an advanced education placed more weight on the milk value trait than farm managers without advanced education. On conventional farms, managers weighted the traits milk value and conformation/udder highly. The conformation/udder and fitness trait complexes were important on organic farms. A new trait called perinatal sucking behavior of newborn calves should be included in the total merit index.
\end{abstract}

Key words: economic weight, discrete choice experiment, Brown Swiss cattle

\section{INTRODUCTION}

The definition of breeding goals is one of the most important steps in the development of efficient breeding programs. Trait selection for inclusion in a breeding goal depends on trait heritability and genetic correlations with other traits as well as the costs and labor required to record phenotypic data and the economic

Received October 18, 2017.

Accepted January 23, 2018.

${ }^{1}$ Corresponding author: Annik_Just@uni-hohenheim.de importance of the trait. For many breeds, a total merit index (TMI) is established that includes both the traits and their relative economic weights (REW). Several methods are available to estimate REW, the most common of which are strictly economic in nature and include objective and profit-oriented methods, such as the herd model (Amer et al., 1996; Fuerst-Waltl et al., 2010), or direct costing and profit functions, which are based on the costs and profits of a production system (Brascamp et al., 1985; Nielsen and Amer, 2007). Critical aspects of these methods are the lack of information on some traits, especially functional traits and new traits that have not been validated monetarily, and the assumption that the sole objective of breeders and farmers is profit maximization. However, the choices of farmers may not be affected only by economic factors, especially on organic farms, where particular importance may be attached to noneconomic aspects such as animal welfare, environmental impacts, and other individual operational characteristics (Nielsen and Amer, 2007).

Alternatively, REW may be derived via nonobjective methods that are based on the subjective assessments and empirical values of experts, breeders, farmers, or consumers. Teegen et al. (2008) and von Rohr et al. (1999) applied the contingent valuation method to estimate REW in horse and pig breeding, respectively. A simple and intuitive approach is to analyze the frequency of the use of sires for AI and link it to the EBV of their traits, which would yield some realized REW (i.e., the relative importance of trait EBV in the past selection of the sires). However, such an approach would fail for new traits, and more sophisticated methods have to be used. Choice experiments are frequently applied to study farmers' preferences for traits. For example, Martin-Collado et al. (2015) applied pairwise comparisons of traits in an online survey to study Australian dairy farmers' preferences for 13 traits. The authors showed that the preferences are heterogeneous with respect to farmer characteristics - that is, they differed for production-focused, functionality-focused, and typefocused farmers. The farmer characteristics were identified by using principal component analysis followed by 
hierarchical cluster analysis. A similar approach was used by Slagboom et al. (2016a,b) to identify farmers' characteristics. An interesting result of Martin-Collado et al. (2015) was that the heterogeneity was intrinsic to farmers and not to production systems or breeds. The results of the study were used in the design of new breeding objectives and selection indices tailored for these 3 farmer types in Australia (Byrne et al., 2016). Choice experiments have also been applied in other species, such as sheep (Byrne et al., 2012; Ragkos and Abas, 2015), pigs (Roessler et al., 2012), and chickens (Bett et al., 2011) and frequently to study farmers' preferences in developing countries (Duguma et al., 2011). Ahlman et al. (2014) and Slagboom et al. (2016a,b) used choice experiments to study Swedish and Danish dairy farmers' preferences for breeding traits, respectively, considering heterogeneous preferences among farmers (i.e., organic and conventional farmers).

A challenge is the proper design of the choice sets. The discrete choice experiment (DCE) has a welldefined theoretical basis in random utility theory (Louviere et al., 2010) and is closely related to natural decision processes. Respondents are given a questionnaire consisting of multiple questions called choice sets, and they are required to choose one alternative from each set, which enables researchers to examine comprehensive decisions. In animal breeding, this method can be used to study farmers' preferences for breeding traits and, based on this, to derive REW by allowing breeders to choose among hypothetical sires with different EBV and semen prices. The assumption is that the sire chosen from the questionnaire will represent the greatest utility for the breeder. This utility is affected by the levels of the attributes of the sires (i.e., hypothetical EBV and semen prices) and by operational characteristics of the farm (e.g., conventional or organic systems). The latter allows for the consideration of heterogeneous preferences among farmers. Naturally, the utility comprises economic aspects but also values the experience, informal background, or future orientation of the farmers. Interactions between the trait EBV of the sires and the characteristics of farms or farmers can be used to determine heterogeneous REW, which is termed "environment-specific REW" throughout this article. These can be used to define environmentspecific breeding goals.

The DCE can also be used to calculate the marginal willingness to pay (MWTP), which describes the amount of money a respondent is willing to pay to obtain an additional nonmonetary attribute (Aizaki et al., 2015) - in this case an improvement in a certain trait by 1 genetic standard deviation. This broadens the assessment of trait importance to include a monetary perspective.
The Brown Swiss cattle breed is a milk-type, dualpurpose breed that is commonly used in southern Germany, and it is reared in conventional as well as organic farming systems, which have their own TMI with different REW. The aim of the present study was to estimate REW and the MWTP using a DCE for Brown Swiss cattle in the state of Baden-Wuerttemberg in southern Germany. The REW were subsequently used to establish an environment-specific TMI and were compared with the REW used in the current TMI for this breed.

\section{MATERIALS AND METHODS}

\section{Survey Design and Data}

A choice experimental design was created with 18 choice sets consisting of 3 hypothetical sires each; 1 sire had to be chosen by the breeder to serve as an average cow in the herd. Seven attributes were defined for the sires; namely, the price for 1 portion of semen (monetary element in euros) and breeding values for the following 6 trait complexes. The milk production value trait complex represented milk, protein, and fat yield. The general beef production value represented daily gain, carcass quality, and slaughter yield. The conformation/udder trait complex consisted of exterior and health of claw, leg, and udder. The fitness trait complex comprised the remaining functional traits (i.e., calving ease, stillbirth, functional longevity, persistency, fertility). The show type trait denoted all exterior traits except udder, claw, and leg exterior. The final trait, perinatal sucking behavior (PSB), was included because insufficient PSB is a serious problem in this breed and shows significant heritability (Maltecca et al., 2007). According to a survey, approximately $7 \%$ of newborn Brown Swiss calves exhibit insufficient PSB in Germany, and the heritability is about 0.15 (C. Dreher and J. Bennewitz, Institute of Animal Science, University Hohenheim, Germany, personal communication). This trait is a putative novel breeding trait. The admissible levels of the breeding values were 100 (mean breeding value), 112 (1 SD above the mean), and 124 (2 SD above the mean), and no breeding value was assumed to be below the mean. The prices for 1 portion of semen were set at $€ 6$ (low cost), $€ 12$ (moderate cost), and $€ 18$ (higher cost). The analytical design was created with the R package "support.CEs" (Aizaki, 2012). Seven orthogonal main effects arrays (1 for each trait and 1 for the semen price) were used to define the first alternative of each choice set, and the same was done for the second and third alternatives. Assignments were performed randomly with different seeds. For each of the 1,000 designs resulting from the different seeds, 500 DCE were simulated, and the average standard errors 
Table 1. Example of a discrete choice set ${ }^{1}$

\begin{tabular}{lccc}
\hline Trait & Sire 1 & Sire 2 & Sire 3 \\
\hline Milk value & ++ & ++ & $\mathrm{O}$ \\
Beef value & + & ++ & + \\
Conformation/udder & $\mathrm{O}$ & $\mathrm{O}$ & ++ \\
Show type & + & $\mathrm{O}$ & $\mathrm{O}$ \\
Fitness & $\mathrm{O}$ & + & + \\
Perinatal sucking behavior & ++ & + & ++ \\
Price $^{2}$ & 12 & 18 & 18 \\
Choice & 6 & 12 & 18 \\
\hline
\end{tabular}

${ }^{1} \mathrm{O},+$, and $++=$ hypothetical breeding values (mean, $1 \mathrm{SD}$, and $2 \mathrm{SD}$, respectively) for the traits of hypothetical sires.

${ }^{2}$ Hypothetical values for the sires' semen ( $€$ /portion).

and the average correlations were recorded between the estimated and true effects. The design with the smallest standard error and highest correlation was chosen for the study, and of the 18 choice sets, 2 questionnaires (A and B) with 9 choice sets each were randomly created to limit the number of choice sets the farmers had to consider. On-farm trial interviews were conducted using the questionnaires to evaluate their comprehensibility, and the results revealed that no adaptation of the initial questionnaires was necessary. Additionally, the reactions of the farmers were generally very positive, indicating a general willingness to cooperate. Following the trial interviews, the questionnaires were sent to 230 managers (respondents) of both conventionally and organically managed farms in southern Germany (Alb region of the state of Baden-Wuerttemberg). Farmers were randomly assigned either questionnaire A or questionnaire $\mathrm{B}$, and every farmer was required to complete 9 choice sets. An example of a choice set is given in Table 1. Questionnaires were sent by mail and were accompanied by an explanation letter with instructions and additional questions about the farming system (e.g., organic or conventional, feeding, daily milking frequency) and the characteristics of the respondents (e.g., level of education). A total of 166 completed surveys were returned and used for the statistical analyses, which resulted in 4,482 data sets [9 choice sets (A or B) $\times 3$ alternatives $\times 166$ respondents].

\section{Conditional Logit Model}

The questionnaires were analyzed with a conditional logit model as follows: $y_{n k i}=1$ if person $n$ chose alternative $i$ from the $k$ th choice set completed by the person, and $y_{n k j}=0$ for the other alternatives, $j \neq i$. It is assumed that random variables $U_{n k i}$ exist such that

$$
y_{n k i}=\left\{\begin{array}{l}
1 \text { if } U_{n k i}>U_{n k j} \text { for all } j \neq i \\
0 \text { otherwise }
\end{array} .\right.
$$

The value $U_{n k i}$ is the utility (or benefit) that person $n$ obtained from choosing alternative $i$ from the $k$ th choice set. It is assumed that the utility can be decomposed as

$$
U_{n k i}=\left(\boldsymbol{\beta}+\Sigma_{s} \gamma_{s} \delta_{n s}\right)^{\prime} \mathbf{a}_{n k i}+\varepsilon_{n k i}
$$

where the vector $\mathbf{a}_{n k i}$ contained the attributes of alternative $i$ from the $k$ th choice set completed by farmer $n ; \boldsymbol{\beta}$ is the vector of the effects of the traits; $\boldsymbol{\gamma}_{s}$ is the vector of interactions between characteristic $s$ describing the farms and the traits; and $\delta_{n s}=1$ if the farm managed by farmer $n$ has characteristic $s$. The variable $\varepsilon_{n k i}$ captures the effect of all unobserved factors that affect the choice of the farmer. As a shorthand,

$$
V_{n k i}=\left(\boldsymbol{\beta}+\Sigma_{s} \gamma_{s} \delta_{n s}\right)^{\prime} \mathbf{a}_{n k i},
$$

where $V_{n k i}$ is called the observable component of the benefit farmer $n$ obtained from choosing alternative $i$ in the $k$ th choice set $C_{k}$. The probability for choosing the alternative $i$ is

$$
P_{n}\left(i \mid C_{k}\right)=\frac{\exp \left(V_{n k i}\right)}{\sum_{j \in C_{k}} \exp \left(V_{n k j}\right)} .
$$

In this conditional logit model, the MWTP for the nonmonetary variable (i.e., the 6 traits) included in the DCE was calculated as

$$
\operatorname{MWTP}=-\frac{b_{f m}}{b_{m}},
$$

where $b_{f m}$ is the estimated coefficient of the nonmonetary variable and $b_{m}$ is the estimated coefficient of the monetary variable price per portion of each sire's semen. Twelve euros per portion of semen was taken as a basis, and the results were reported in euros for a portion of semen and per genetic standard deviation of the specific trait. To estimate the coefficients for all traits as well as the interactions, the $\mathrm{R}$ package "survival" and the function "clogit" were used (Aizaki, 2012). Interactions with $P>0.01$ were excluded from the model step by step, but if the interaction between a farm characteristic and a trait was significant, the interaction of this characteristic with all traits was retained. To derive the MWTP, the R function "mwtp" was used (Aizaki et al., 2015). Farm managers were classified as educated (EF; basic 3-yr apprenticeship) or advanced educated (AEF; basic 3-yr apprenticeship plus $2 \mathrm{yr}$ of extra schooling), and the farming systems were classified as conventional or organic. 
Table 2. Estimated coefficients for traits and significant interactions between traits and the individual and operational characteristics of the respondents using a conditional logit regression model

\begin{tabular}{lccc}
\hline Item & Coef $^{1}$ & SE $($ Coef $)$ & $P$-value \\
\hline Milk value & 0.76 & 0.09 & $<0.001$ \\
Beef value & -0.07 & 0.06 & 0.219 \\
Conformation/udder & 1.13 & 0.06 & $<0.001$ \\
Show type & 0.12 & 0.06 & 0.055 \\
Fitness & 0.59 & 0.06 & $<0.001$ \\
Perinatal sucking behavior & 0.56 & 0.06 & $<0.001$ \\
Price & -0.31 & 0.07 & $<0.001$ \\
Fitness $\times$ organic & 0.73 & 0.25 & 0.004 \\
Milk value $\times$ advanced farmer education & 0.42 & 0.11 & $<0.001$ \\
\hline${ }^{1}$ Coef $=$ estimated coefficients for traits and significant interactions from the discrete choice experiment using
\end{tabular}

a conditional logit regression model.

\section{RESULTS}

Table 2 shows the coefficients and $P$-values estimated for the 7 attributes ( 6 traits and the semen price) and 2 significant interactions (i.e., between the trait fitness and the farming system and between the trait milk value and the education level of the farm manager) using the conditional logit regression model. Five of the attributes (milk value, conformation/udder, fitness, PSB, and the monetary element price for 1 portion of semen) showed a significant effect on the choice behavior of the respondents $(P<0.001)$. The 2 traits of beef value and show type were not significant. The conformation/ udder trait complex showed the highest estimated coefficient followed by the trait complexes of milk value and fitness and the trait PSB (in descending order), and a negative coefficient was estimated for the price. The coefficient for the interaction between organic farming systems and the fitness trait complex was 0.73 , and coefficient for the interaction between the milk value trait and AEF was 0.42. Based on the 2 significant interactions, REW were calculated for 4 environments, which were defined by the combinations of conventional and organic farming systems and EF and AEF (Table 3). Conventional AEF considered the trait of milk value to be $9 \%$ more important than conventional $\mathrm{EF}$, and AEF of organic farms assigned a weight of $17 \%$ to the milk value, also $9 \%$ higher than EF of organically managed farms. The highest REW were estimated for the conformation/udder trait complex for the environment of conventional farming system and EF. Organic farm managers weighted the conformation/udder trait complex approximately $30 \%$, and they weighted the fitness trait complex approximately $35 \%$, which was twice the weight given by conventional farm managers. The REW for the trait PSB were between 14 and $21 \%$, and this trait seemed to be more important for $\mathrm{EF}$, whereas no difference was observed between the 2 farming types. Show type was not very important in any environment, and beef value was even less so. The REW for beef value was slightly negative for conventional and slightly positive for organic farming systems.

Table 4 shows the REW estimated in this study, the REW used in the current conventional TMI (Bayrische Landesanstalt für Landwirtschaft, 2016; Fuerst-Waltl et al., 2016), and the REW used in the current organic TMI (Bayrische Landesanstalt für Landwirtschaft, 2017). The REW for fitness and constitution derived from the DCE were in similar range as the current conventional TMI and organic TMI. In the conventional system, the DCE REW for fitness was approximately $6 \%$ higher than in the current TMI. The DCE-derived REW included the new traits PSB and show type, which were not included in the current TMI; the addition of these traits reduced the REW of milk value and beef value compared with the current TMI. The DCE REW of the milk value is lower in both systems, and the DCE REW for beef value equals one quarter of the currently used REW in the organic TMI.

Table 5 shows the results of the MWTP estimation. Farm managers were willing to pay approximately $€ 3.60$ more for a portion of semen and an improvement of 1 genetic standard deviation of the conformation/ udder trait complex independent of farming system and level of education. The AEF group of conventional

Table 3. Environment-specific relative economic weights (\%) of traits depending on the farming system and level of education of the farm manager ${ }^{1}$ using discrete choice experiment data

\begin{tabular}{lrrrrrr}
\hline & \multicolumn{2}{c}{ Conventional } & & \multicolumn{2}{c}{ Organic } \\
\cline { 2 - 3 } \cline { 6 - 7 } Trait & EF & AEF & & EF & AEF \\
\hline Milk value & 25 & 34 & & 8 & 17 \\
Beef value & -2 & -2 & & 3 & 2 \\
Conformation/udder & 35 & 33 & & 30 & 29 \\
Show type & 4 & 3 & & 4 & 3 \\
Fitness & 17 & 18 & & 35 & 34 \\
Perinatal sucking behavior & 21 & 14 & & 20 & 15 \\
\hline
\end{tabular}

${ }^{1} \mathrm{EF}=$ farm manager without an advanced education; $\mathrm{AEF}=$ farm manager with an advanced education. 
Table 4. Relative economic weights (\%) of traits depending on the farming system compared with current relative economic weights (\%) used for the conventional and organic total merit index (TMI)

\begin{tabular}{|c|c|c|c|c|}
\hline \multirow[b]{2}{*}{ Trait } & \multicolumn{2}{|c|}{ Conventional TMI } & \multicolumn{2}{|c|}{ Organic TMI } \\
\hline & Current $^{1}$ & $\mathrm{DCE}^{2}$ & Current $^{3}$ & DCE \\
\hline Milk value & 50 & 29.5 & 25 & 12.5 \\
\hline Beef value & 5 & -2 & 10 & 2.5 \\
\hline Fitness/constitution ${ }^{4}$ & 45 & 51.5 & 65 & 64 \\
\hline Show type & - & 3.5 & - & 3.5 \\
\hline Perinatal sucking behavior & - & 17.5 & - & 17.5 \\
\hline \multicolumn{5}{|c|}{ 19Barische Landesanstalt für Landwirtschaft (2016). } \\
\hline \multicolumn{5}{|c|}{${ }^{2}$ Discrete choice experiment (this study). } \\
\hline \multicolumn{5}{|c|}{${ }^{3}$ Bayrische Landesanstalt für Landwirtschaft (2017). } \\
\hline
\end{tabular}

farms were willing to pay $€ 3.95$ more for the trait of milk value, whereas the EF group of organic farms were willing to pay only €0.88 more for a portion of semen. Managers of organic farms were willing to pay approximately €0.35 more for the sires' semen and an improvement of 1 standard deviation of the beef value trait, whereas managers of conventional farms were not willing to pay for a genetic gain in the trait $(-€ 0.23)$. Managers of organic farms were willing to pay more than twice as much money as conventional farm managers for an improvement in fitness. For the trait of PSB, AEF managers, independent of farming system, were willing to pay approximately $€ 1.80$ more for a portion of semen to improve the trait by 1 genetic standard deviation, whereas EF managers were willing to pay approximately €2.19 more.

\section{DISCUSSION}

A DCE approach was used to determine the REW and the MWTP for trait complexes in Brown Swiss cattle in southern Germany. In discussing the results

Table 5. Marginal willingness to pay $^{1}(€)$ for the traits depending on the farming system and level of education of the farm manager ${ }^{2}$ using discrete choice experiment results

\begin{tabular}{lrrrrrr}
\hline & \multicolumn{2}{c}{ Conventional } & & \multicolumn{2}{c}{ Organic } \\
\cline { 2 - 3 } \cline { 6 - 7 } Trait & \multicolumn{2}{c}{ EF } & AEF & & \multirow{2}{*}{ EF } & \multirow{2}{*}{ AEF } \\
\hline Milk value & 2.58 & 3.95 & & 0.88 & 2.25 \\
Beef value & -0.21 & -0.25 & & 0.37 & 0.33 \\
Conformation/udder & 3.54 & 3.90 & & 3.34 & 3.70 \\
Show type & 0.43 & 0.34 & & 0.46 & 0.36 \\
Fitness & 1.68 & 2.10 & & 4.00 & 4.40 \\
Perinatal sucking behavior & 2.09 & & 1.70 & & 2.28 & 1.90 \\
\hline
\end{tabular}

${ }^{1}$ Mean price for 1 portion of a sire's semen with $€ 12$ as a basis. Results are in euros for 1 portion of semen and per genetic SD of the trait.

${ }^{2} \mathrm{EF}=$ farm manager without an advanced education; $\mathrm{AEF}=$ farm manager with an advanced education. of the study, it is important to note that this approach is not purely economically motivated, so if the aim of cattle breeding is to maximize profit, the results of the DCE should be considered with some caution. Profitoriented methods aim to maximize profit for farmers but do not always reflect the farmers' aims. In the DCE method, the opinions of farmers can be included, so the estimated REW are more likely to reflect the aspirations of the farmers. At the same time, the amount of money a farmer is willing to pay may not completely represent the effects of trait improvements on the profitability of the farm. Thus, DCE could be used to complement profit-oriented methods to obtain REW, and the putative differences in the results of these 2 alternative approaches can be evaluated and discussed with the farmers.

\section{DCE Questionnaire Structure}

Considering the collection of the data for the DCE, the selection of the traits to be included in the questionnaires was particularly important. The chosen traits should not be random, meaning that they should be known or of special interest to breeders, and trait complexes, such as the milk value (milk yield, protein, and fat content), should be commonly understood or otherwise explained to the respondents. In addition, the scope of the choice sets should not be too complex, as too many traits per set can overwhelm the respondents, which may negatively affect the choice behavior (Auspurg and Liebe, 2011). As a result, the respondent might too often choose the one alternative with the greatest personal utility or might refuse to participate completely. Therefore, to ensure cooperation, it is necessary to select meaningful traits, perform trial interviews in person on the farm, explain the motivation for this kind of experiment, and limit the scope of the questionnaire sets. It seems that the number of traits 
in the present DCE was not too high, which can be deduced from the relatively high number of returned questionnaires and from the results of the on-farm trial interviews. However, it would naturally be better to include more traits in the questionnaires to obtain a more differentiated picture of single-trait REW. For example, the milk value trait in this study included milk fat and protein yield, but it can reasonably be assumed that the REW of these 3 subtraits would differ, and the same holds true for the functional traits. A weak point of the DCE questionnaire design was that the trait PSB was the only trait that was not embedded in a trait complex. This was done because before this experiment, it was unknown whether breeders would prefer to have PSB included as a new trait in the TMI. Including PSB as a subtrait in a trait complex would not have informed us about the farmers' preferences for this specific trait. However, it is reasonable to assume that the REW of PSB would be lower if other traits in the TMI were treated separately and not included in trait complexes. This, however, would greatly increase the number of traits, risking the problems associated with too many choices as listed above.

\section{Results of the DCE}

The results of this study confirm the heterogeneity in the farmers' trait preferences (Tables 2-4), which was also found by, for example, Martin-Collado et al. (2015), Ahlman et al. (2014), and Slagboom et al. (2016a,b). The farms were classified using external information (i.e., production system and level of farmers' education). More sophisticated classification methods were applied by Martin-Collado et al. (2015) and Slagboom et al. (2016a,b). This requires the collection of farmers and farm profile factors, which were not included in our questionnaires.

The managers of organic farming systems placed more weight on the fitness trait complex and less on milk value, and the MWTP for the fitness trait complex was twice as high compared with conventional farm managers. This might be due to the need for more robust cows because medical treatment options are reduced in organic systems. In addition, a high genetic milk value is less important in organic systems because there are generally fewer opportunities to realize high milk yield due to feeding restrictions. The conformation/udder trait complex is very important for both farming systems. Ahlman et al. (2014) investigated the differences for traits between organic and conventional farming systems in Sweden using questionnaires. In general, the same traits were important in both systems, with some differences in the relative importance of traits. Organic farm managers put more weight on health traits and less on milk production, which is in agreement with the results of the present study. Slagboom et al. (2016a) identified a higher priority of production traits for organic farmers compared with conventional farmers in Denmark, which is in contrast to the results of Ahlman et al. (2014) and to our results. The explanations for these results given by Slagboom et al. (2016a) were that farmers wanted to improve the traits that are more problematic in their herds. Because the average milk yield and the disease incidences were both lower in organic herds compared with the conventional herds included in their study, organic farmers ranked milk yield higher than the conventional farmers did.

In the present study, the second tier of the farm characteristics was the education of the farmers. The AEF gave more weight to milk value and less to the new trait of PSB. One explanation could be that insufficient PSB is less severe on farms with AEF, but this could not be demonstrated in the current study.

The currently used TMI was recently adjusted based on newly estimated economic weights of traits and discussions with the breeders (Fuerst-Waltl et al., 2016). In general, both REW (the currently used and the DCE REW) agree to a large extent for both farming systems (Table 4). However, it seems that farmers wish to include the new trait PSB, which goes mainly at the costs of the weight of milk in the TMI. Currently, routine data recording is implemented for the trait PSB by the breeding organization, and farmers must assess the sucking behavior of newborn calves using 4 categories (no, weak, normal, and strong sucking reflex). Once a suitable data structure and genetic evaluation (i.e., EBV calculation) have been established, this trait will be included in the TMI, and the results of the current DCE might be used to determine the weight that this trait should receive in the adjusted TMI.

\section{CONCLUSIONS}

The DCE is a suitable choice experiment method to derive REW for a limited number of trait complexes. It can be viewed as a bottom-up approach because the REW are based on the responses of farmers to structured questionnaires. Thus, this method is not strictly economically driven and can be used in combination with purely profit-orientated approaches. The DCE is flexible in the sense that heterogeneous farmers' preferences can be modeled straightforwardly. Thus, it allows for the estimation of environment-specific REW, which can in turn be used to develop an environment-specific TMI. It is a suitable method to judge the importance of traits for farmers, especially traits that have not been economically evaluated, and hence might guide breeding organizations in their decisions to include these traits 
in the TMI. Furthermore, the DCE can be regularly used to assess whether the current TMI reflects the expectations of farmers and to indicate where adjustments are needed. By comparing the REW obtained by the DCE with those that are currently used in the German Brown Swiss population, it became obvious that they agree to a large extent except that farmers wish to have the new trait PSB included in the TMI. The addition of PSB would reduce the REW for the milk trait complex.

\section{ACKNOWLEDGMENTS}

The authors thank the farmers who provided the data for this study by participating in the discrete choice experiment and the Rinderunion Baden-Württemberg e.V. (Herbertingen, Germany) breeding organization for their support in coordinating the personal interviews. The manuscript has benefitted from the critical and helpful comments of 2 anonymous reviewers. A. Just was funded by the H. Wilhelm Schaumann Stiftung (Hamburg, Germany).

\section{REFERENCES}

Ahlman, T., M. Ljung, L. Rydhmer, H. Röcklinsberg, E. Strandberg, and A. Wallenbeck. 2014. Differences in preferences for breeding traits between organic and conventional dairy producers in Sweden. Livest. Sci. 162:5-14.

Aizaki, H. 2012. Basic functions for supporting an implementation of choice experiments in R. J. Stat. Soft. 50:2 https://doi.org/10 $18637 /$ jss.v050.c02

Aizaki, H., T. Nakatani, and K. Sato. 2015. Stated Preference Methods Using R. CRC Press, Boca Raton, FL.

Amer, P. R., A. Kaufmann, and N. Künzi. 1996. Breed choice and pricing system implications for farmers and political institutions from a Swiss cattle farm model. Pages 253-258 in Livestock Farming Systems: Research, Development, Socio-Economics and the Land Manager. EAAP Publication No. 79. J. B. Dent, M. J. McGregor, and A. R. Sibbald, ed. Wageningen Academic Publishers, Wageningen, the Netherlands.

Auspurg, K., and U. Liebe. 2011. Choice-Experimente und die Messung von Handlungsentscheidungen in der Soziologie. Kolner Z. Soz. Sozialpsychol. (Aufl) 63:301-314.

Bayrische Landesanstalt für Landwirtschaft (LfL). 2016. Wirtschaftliche Gewichte pro genetischer Standardabweichung (\%) und theoretischer Selektionserfolg in $\mathrm{kg}$ (Milch, Fett, Eiweiß) bzw. ZWPunkten (Fleisch und Fitness) pro Generation bei Selektion nach GZW beim Braunvieh. Accessed Apr. 26, 2017. https://www.lfl .bayern.de/mam/cms07/itz/dateien/zwsrind_gesamtzuchtwert _tab2.pdf.

Bayrische Landesanstalt für Landwirtschaft (LfL). 2017. Der Ökologische Gesamtzuchtwert für Braunvieh. Accessed Apr. 26, 2017. http://www.lfl.bayern.de/mam/cms07/itz/bilder/zwsrind _oekbv1704.pdf.
Bett, H. K., R. C. Bett, K. J. Peters, A. K. Kahi, and W. Bokelmann. 2011. Estimating farmers' preferences in selection of indigenous chicken genetic resources using non-market attributes. Anim. Genet. Resour. 49:51-63.

Brascamp, E. W., C. Smith, and D. R. Guy. 1985. Derivation of economic weights from profit equations. J. Anim. Sci. 40:175-179.

Byrne, T. J., P. R. Amer, P. F. Fennessy, P. Hansen, and B. W. Wickham. 2012. A preference-based approach to deriving breeding objectives: Applied to sheep breeding. Animal 6:778-788.

Byrne, T. J., B. F. S. Santos, P. R. Amer, D. Martin-Collado, J. E. Pryce, and M. Axford. 2016. New breeding objectives and selection indices for the Australian dairy industry. J. Dairy Sci. 99:81468167.

Duguma, G., T. Mirkena, A. Haile, A. M. Okeyo, M. Tibbo, B. Rischkowsky, J. Sölkner, and M. Wurzinger. 2011. Identification of smallholder farmers and pastoralists' preferences for sheep breeding traits: Choice model approach. Animal 5:1984-1992.

Fuerst-Waltl, B., R. Baumung, C. Fuerst, A. Köck, W. Obritzhauser, H. Schwarzenbacher, J. Sölkner, A. Willam, P. Winter, and C. Egger-Danner. 2010. Gesundheitsmonitoring Rind: Entwicklung einer Zuchtwertschätzung für Gesundheitsmerkmale. Final report of the research project 100250 BMLFUW-LE.1.3.2/0043-II/1/2007. Accessed Dec. 7, 2017. https://www.dafne.at/prod/dafne_plus_common/attachment _download/327edc77f1bf0e0e7a8de7e3a92e0a5d/Endbericht _Forschungsprojekt_BMLFUW_100250_inkl.Anlagen.pdf.

Fuerst-Waltl, B., C. Fuerst, W. Obritzhauser, and C. Egger-Danner. 2016. Sustainable breeding objectives and possible selection response: Finding the balance between economics and breeders' preferences. J. Dairy Sci. 99:9796-9809.

Louviere, J., T. Flynn, and R. Carson. 2010. Discrete choice experiments are not conjoint analysis. J. Choice Modelling 3:57-72.

Maltecca, C., A. Rossoni, C. Nicoletti, E. Santus, K. A. Weigel, and A. Bagnato. 2007. Estimation of genetic parameters for perinatal sucking behavior of Italian Brown Swiss calves. J. Dairy Sci. 90:4814-4820.

Martin-Collado, D., T. J. Byrne, P. R. Amer, B. F. S. Santos, M. Axford, and J. E. Pryce. 2015. Analyzing the heterogeneity of farmers' preferences for improvements in dairy cow traits using farmer typologies. J. Dairy Sci. 98:4148-4161.

Nielsen, H. M., and P. R. Amer. 2007. An approach to derive economic weights in breeding objectives using partial profile choice experiments. Animal 1:1254-1262.

Ragkos, A., and Z. Abas. 2015. Using the choice experiment method in the design of breeding goals in dairy sheep. Animal 9:208-217.

Roessler, R., P. Herold, H. Momm, and A. Valle Zárate. 2012. Organisation of breeding under difficult framework conditions-The case of smallholder pig breeding in mountainous areas in Northwest Vietnam. Arch. Tierz. 55:590-602.

Slagboom, M., M. Kargo, D. Edwards, A. C. Sørensen, J. R. Thomasen, and L. Hjortø. 2016a. Organic dairy farmers put more emphasis on production traits than conventional farmers. J. Dairy Sci. 99:9845-9856.

Slagboom, M., M. Kargo, D. Edwards, A. C. Sørensen, J. R. Thomasen, and L. Hjortø. 2016b. Herd characteristics influence farmers' preferences for trait improvements in Danish Red and Danish Jersey cows. Acta Agric. Scand. A Anim. Sci. 66:177-182.

Teegen, R., C. Edel, and G. Thaller. 2008. Bewertung der Zuchtzielmerkmale des Trakehner Verbandes mit Hilfe der kontingenten Befragungsmethode ("Contingent Valuation Method", CV). Zuchtungskunde 80:99-113.

von Rohr, P., A. Hofer, and N. Künzi. 1999. Economic values for meat quality traits in pigs. J. Anim. Sci. 77:2633-2640. 